\title{
Cultivo de brócolos de inflorescência única no verão em plantio direto ${ }^{1}$
}

\author{
Raphael Augusto de C e Melo²; Nuno R Madeira ${ }^{3}$; José Ricardo Peixoto ${ }^{4}$ \\ ${ }^{2}$ Embrapa Cerrados, C. Postal 08233, 73310-970 Planaltina-DF; ${ }^{3}$ Embrapa Hortaliças, C. Postal 218, 70359-970 Brasília- \\ DF; ${ }^{4}$ UnB-FAMV; raphael.melo@cpac.embrapa.br
}

\section{RESUMO}

O experimento foi conduzido no delineamento de blocos casualizados, em arranjo de parcelas subdivididas com três repetições. As parcelas foram constituídas por plantas de cobertuta [milheto (Pennisetum glaucum), milho (Zea mays), consórcio de milho com mucuna-preta preta (Estilozobium aterrimum), sorgo-sudão (Sorghum bicolor X S. sudanense)] além do plantio convencional (PC) (solo preparado com aração e gradagem após pousio). As cultivares Avenger, Demoledor, Grandisimo, Green Storm Bonanza, Legacy e o material HECB-01-06, constituiram as sub-parcelas. Não houve diferença significativa entre o plantio direto $(\mathrm{PD})$ e o PC quanto à produção de brócolos. Houve diferença significativa entre cultivares para as variáveis avaliadas. Com relação às cultivares, Avenger obteve maior produtividade $\left(13,2 \mathrm{tha}^{-1}\right)$, peso médio de inflorescências (458 g), diâmetro $(15,3 \mathrm{~cm})$ e melhor qualidade das inflorescências (índice de aspecto visual de 4,0). Portanto, considerando-se as vantagens do $\mathrm{PD}$ com a manutenção de níveis de produtividade equivalentes às obtidas no PC, deve-se recomendar sua adoção.

Palavras-chave: Brassica oleracea var. italica, sistemas de cultivo, época de plantio, produtividade.

\begin{abstract}
Single head broccoli cultivars production in summer under no-tillage

The objective of this work was to evaluate single head broccoli cultivars production in summer under no-tillage (NT). The experimental design was randomized blocks with a split-plot design and three replicates. The plots were constituted by the cover crops: pearl millet (Pennisetum glaucum), corn (Zea mays), a mix of corn and black velvet-bean (Estilozobium aterrimum), sorghum sudangrass (Sorghum bicolor X S. sudanense), besides the conventional tillage (CT) - soil after fallow prepared with plow and disk harrow. Cultivars Avenger, Demoledor, Grandisimo, Green Storm Bonanza, Legacy and the material HECB-01-06, represented the sub-plots. No differences were found among NT and CT concerning broccoli yield. There were significant differences between cultivars for the evaluated variables. The cultivar Avenger presented the highest yield (13.2 $\left.\mathrm{t} \mathrm{ha}^{-1}\right)$, average weight $(458 \mathrm{~g})$, diameter $(15.3 \mathrm{~cm})$ and quality of the curds (index for visual aspect of 4.0). Therefore, considering the benefits proportionated by NT, with the maintenance of high productive levels, equivalent at $\mathrm{CT}$, its adoption is recommended.
\end{abstract}

Keywords: Brassica oleracea var. italica, crop systems, planting season, yield.

\section{(Recebido para publicação em 28 de novembro de 2008; aceito em 19 de fevereiro de 2010)}

(Received on November 28, 2008; accepted on February 19, 2010)

$\mathrm{O}$ brócolos (Brassica oleracea $\mathrm{L}$. var. italica Plenck) com uma única inflorescência verde foi introduzido nos EUA por imigrantes italianos durante o início do século 20 e se tornou uma hortaliça muito popular, espalhando-se pelo mundo nos últimos 50 anos (Dixon $\&$ Dickson, 2006). Por ser adequado ao congelamento e comercialização em balcões frigoríficos, o brócolos do tipo inflorescência única apresenta importância crescente no mercado brasileiro (Melo et al., 1994). As cultivares do tipo inflorescência única utilizadas no Brasil, em sua totalidade, são originárias de países de clima temperado e por isso apresentam dificuldade de adaptação às condições climáticas, especialmente no verão.

No Brasil, o plantio de verão geralmente é problemático, devido ao excesso de chuvas e calor durante o ciclo, com maior incidência de pragas e doenças, especialmente na época da colheita. O produto final colhido sob essas condições tem aspecto comercial inferior, com cabeças menores, mais leves, de coloração mais clara, granulação maior, mais grossa, de pior textura e menor conservação pós-colheita (Tavares, 2000).

A avaliação do potencial de cultivares em diferentes regiões agroclimáticas, além de proporcionar sustentabilidade a pesquisas subseqüentes, é imprescindível para o aumento da rentabilidade das culturas, diretamente relacionado ao uso de cultivares geneticamente superiores em termos de produtividade e outras características agronômicas relevantes (Santa Catarina, 2001). O uso de cultivares tolerantes a temperaturas altas permite a ampliação das regiões de cultivo, épocas de plantio e período de oferta do produto no mercado, além de aumentar a rentabilidade da cultura (Trevisan et al., 2003).

Freitas (2002) define o Sistema Plantio Direto (SPD) como um sistema de manejo sustentável do solo e da água que visa otimizar a expressão do potencial genético das plantas cultivadas, compreendendo um complexo integrado de processos fundamentado em três

${ }^{1}$ Parte da dissertação do primeiro autor apresentada ao programa de pós-graduação na UnB, para obtenção do título de Mestre em Ciências Agrárias, área de concentração em Produção Vegetal. 
requisitos básicos: o revolvimento mínimo do solo, restrito à cova ou sulco de plantio; a diversificação de espécies pela rotação de culturas; e a manutenção de resíduos vegetais com o uso de culturas específicas para formação de palhada na superfície do solo.

Em hortaliças, é complexo o estabelecimento de um SPD a longo prazo, à semelhança do que ocorre em grãos. Tem-se verificado o plantio de culturas sobre a palhada, sem revolvimento do solo (aração e gradagem ou encanteiramento), porem não permanentes, devido às características intrínsecas à olericultura, quais sejam: mercado muito dinâmico, com mudanças na tomada de decisão quanto a "o que plantar" e “quando plantar"; baixa produção de palhada pela grande maioria das hortícolas para permanecer com o SPD; adaptabilidade restrita ao plantio sem revolvimento para espécies como, por exemplo, cenoura e batata; muitas unidades com área restrita e, consequentemente, uso intensivo da propriedade. Por outro lado, têm-se alguns facilitadores para efetuar o cultivo de hortaliças em plantio direto, sem revolvimento, ainda que não se atinja o estágio de um sistema de plantio direto em longo prazo, dentre eles: a necessidade de mitigar os processos erosivos causados pelo excessivo revolvimento de solo na época chuvosa nos sistemas convencionais; a oportunidade de efetuar rotação de culturas, reduzindo os problemas fitossanitários; a amenização dos picos de temperatura proporcionados pela palhada, conferindo melhores condições de microclima para algumas espécies hortícolas; a facilidade de produzir palhada na época das chuvas para a produção de hortaliças com irrigação na época seca, prática já utilizada na maioria das unidades produtivas.

Um dos fatores limitantes para a adoção do SPD em hortaliças é a limitada diversidade botânica nas espécies de sucessão/antecipação à cultura a ser explorada economicamente. Isso tem causado um aumento na incidência de pragas e doenças, principalmente as de solo, no Cerrado. Como alternativa, tem-se o uso de plantas de cobertura, com ciclos reduzidos e tolerância à seca, permitindo aproveitar a umidade resi- dual; estabelecimento de cobertura com resíduos (palhada) persistentes e que gerem renda, direta ou indiretamente via transformação agroindustrial (Landers, 1995; Spehar \& Landers, 1997).

A definição de prioridade na seleção das espécies de cobertura deve basear-se no seu rápido estabelecimento, tolerância ao déficit hídrico, produção de biomassa, disponibilidade, fertilização e ciclagem de nutrientes de utilização humana e animal. As espécies de cobertura visam preencher o vazio existente na entressafra, com o aproveitamento do resíduo de umidade em antecipação ou sucessão ao cultivo principal (Spehar \& Lara Cabezas, 2001). Outra importante função das plantas de cobertura, principalmente na horticultura, é que estas podem modificar as variações de temperatura no interior do solo, particularmente próximo da superfície, contribuindo para um melhor desenvolvimento das plantas e incremento produtivo. No verão, temperaturas registradas às 14 horas, na superfície do solo, freqüentemente excedem $40^{\circ} \mathrm{C}$ no $\mathrm{PC}$, ficando em torno de 35 e de $30^{\circ} \mathrm{C}$, respectivamente, no PD (Sidiras \& Pavan, 1986), citados por Gasparim et al., 2005). O objetivo deste trabalho foi avaliar a produção de cultivares de brócolos de inflorescência única no verão em PD estabelecido durante um ano agrícola.

\section{MATERIAL E MÉTODOS}

O trabalho foi conduzido no campo experimental da Embrapa Hortaliças, a $15^{\circ} 56^{\prime} 00^{\prime \prime}$ latitude sul, $48^{\circ} 08^{\prime} 00^{\prime \prime}$ longitude oeste e altitude $997,6 \mathrm{~m}$, durante o verão, de novembro de 2006 a março de 2007. O solo foi classificado como Latossolo Vermelho Escuro Álico, textura média (Embrapa, 1999). A análise química desse solo, realizada antes da implantação do experimento, revelou: $\mathrm{pH}$ (água) $=5,75$; em $\mathrm{cmol}_{\mathrm{c}} \mathrm{dm}^{-3}: \mathrm{Al}=$ 0,$2 ; \mathrm{Ca}+\mathrm{MG}=5,4 ; \mathrm{Ca}=4,2 \mathrm{e} \mathrm{MG}=1,2$; e em dm${ }^{-3}: P=18,5 ; \mathrm{K}=270$ e $46,60 \mathrm{~g}$ $\mathrm{dm}^{-3}$ de matéria orgânica.

Utilizou-se o delineamento de blocos casualizados em parcelas subdivididas com três repetições. Cada planta de cobertura, milheto (Pennisetum glaucum), milho (Zea mays), consórcio de milho com mucuna-preta preta (Estilozobium aterrimum) e sorgo-sudão (Sorghum bicolor X S. sudanense), além do cultivo convencional (solo após pousio preparado com aração e gradagem), constituiu uma parcela, sendo nelas distribuídas as cultivares Avenger, Demoledor, Grandisimo, Green Storm Bonanza, Legacy e o material HECB-01-06 (híbrido experimental em fase de desenvolvimento do programa de melhoramento da Embrapa Hortaliças), constituindo as sub-parcelas. A unidade experimental foi composta de 14 plantas (duas linhas com sete plantas cada), arranjadas em linhas simples, em área total de 4,9 m², plantadas no espaçamento de $0,7 \mathrm{~m}$ entre linhas e $0,5 \mathrm{~m}$ entre plantas. Os dados foram obtidos de 8 plantas úteis por parcela.

O semeio das plantas de cobertura foi feito a lanço em 1 de novembro de 2006, conforme recomendações de Burle et al. (2006). Aplicou-se aos 37 dias, em função de dificuldades operacionais, $50 \mathrm{~kg} \mathrm{ha}^{-1} \mathrm{de} \mathrm{N}$, fazendo-se uso de uréia, distribuída a lanço, visando correção de deficiência nutricional. A área destinada ao sistema convencional permaneceu em pousio durante o desenvolvimento das plantas de cobertura. O manejo das plantas de cobertura foi realizado em 27 de dezembro de 2006 (57 dias após semeadura), com o implemento Trimax, que consiste num picador/desintegrador utilizado para destruição de restos culturais. Foram retiradas amostras das palhadas das plantas de cobertura para análise de matéria seca, com três repetições por parcelas, utilizando um quadrado de 1 x $1 \mathrm{~m}$ e acondicionamento em sacos, pesados e secos em estufa a $65^{\circ} \mathrm{C}$, até peso constante após 72 horas.

O preparo do solo com aração e gradagem para o sistema convencional, que se encontrava em pousio quando do desenvolvimento das plantas de cobertura, ocorreu no mesmo dia do manejo destas. A semeadura do brócolos foi realizada em 8 de dezembro de 2006, utilizando o substrato comercial Plantmax. A irrigação por microaspersão foi empregada até o momento do transplante. Foram abertas covas para o transplante, com diâmetro de $15-20 \mathrm{~cm}$ e profundidade de $10 \mathrm{~cm}$ em 28 de dezembro. A adubação de base foi de $2 \mathrm{t}$ de cama de frango, 60 
$\mathrm{kg} \mathrm{ha}^{-1}$ de N, $400 \mathrm{~kg} \mathrm{ha}^{-1}$ de $\mathrm{P}_{2} \mathrm{O}_{5}, 150$ $\mathrm{kg} \mathrm{ha}^{-1}$ de $\mathrm{K}_{2} \mathrm{O}$ e $3 \mathrm{~kg} \mathrm{ha}^{-1}$ de $\mathrm{B}$, incorporados nas covas, de acordo com as recomendações de Trani et al. (1996). O transplante ocorreu no dia 16 de janeiro de 2007, vinte dias após o manejo das plantas de cobertura.

Durante a condução do experimento, foram realizadas adubações em cobertura com aplicações parceladas de $200 \mathrm{~kg} \mathrm{ha}^{-1}$ de N, aos 24 dias após o transplante (DAT) e no início da emissão da inflorescência, aos 42 DAT, além de uma adubação foliar com molibdênio aos 36 DAT. Os demais procedimentos fitotécnicos para o controle fitossanitário e condução do experimento foram os normalmente recomendados para a cultura.

Foram colhidas as inflorescências centrais, com corte na base da primeira folha no momento em que a inflorescência atingia seu tamanho máximo, ainda compacta e com grânulos bem fechados (Seabra Júnior, 2005). A colheita iniciou aos 57 DAT, finalizando aos 98 DAT, realizando-se duas colheitas semanais. Foram avaliados a produtividade total em tha-1 ${ }^{-1}$, produtividade comercial (plantas com peso acima de $100 \mathrm{~g}$ e índice de aspecto visual com nota mínima 2) em $\mathrm{t} \mathrm{ha}^{-1}$, peso médio $(\mathrm{g})$, diâmetro $(\mathrm{cm})$, granulometria $(\mathrm{mg})$, índice de aspecto visual das inflorescências, temperatura do solo, primeira colheita realizada, ciclo médio e distribuição semanal da colheita. Determinou-se o índice de aspecto visual de inflorescências de brócolos, baseado nos defeitos descritos na classificação de couve-flor do programa brasileiro para a melhoria dos padrões comerciais e embalagens de hortigranjeiros da CEAGESP (2000). Com esta finalidade empregou-se uma escala de notas variando de 1 a 5 , onde $1=$ extremamente defeituosas, não comerciais; $2=$ comerciais defeituosas; $3=$ moderadamente defeituosas; $4=$ levemente defeituosas; $5=$ sem defeitos aparentes. A granulometria das inflorescências foi avaliada retirando-se três inflorescências de cada repetição. Avaliou-se a correlação entre o peso e o tamanho dos botões florais, de modo a facilitar a avaliação da granulometria, tanto para este trabalho como para trabalhos futuros com brócolos de inflorescência única. As in- florescências foram divididas em quatro quadrantes, dos quais foram retirados 10 botões florais, totalizando 40 botões, que foram pesados e medidos através de paquímetro digital e balança de precisão. Ainda, tomou-se o peso de 60 botões florais escolhidos ao acaso, divididos em 6 grupos de 10. Foi calculada a correlação entre altura dos 40 botões e peso dos 100 botões retirados, em uma escala de -1 a 1 . Assim, quanto mais próximo de 1 , maior a correlação entre altura e peso dos botões florais. As leituras de temperatura do solo foram realizadas durante a fase de expansão e desenvolvimento das folhas, segundo Kimoto (1993). As medições foram realizadas às $14 \mathrm{~h}$ no centro das parcelas (plantas de cobertura) em cada repetição, sendo medidas à superfície e nas profundidades de 5 , 10,15 e $20 \mathrm{~cm}$.

Os dados originais foram submetidos à análise de variância ao nível de $5 \%$ de probabilidade. As médias foram comparadas, entre si, utilizando o teste de Scott-Knott. Foi utilizado o Software Sisvar (Ferreira, 1999).

\section{RESULTADOS E DISCUSSÃO}

As plantas de cobertura avaliadas obtiveram baixas produtividades de matéria seca, quando comparadas a resultados obtidos em condições semelhantes no Cerrado, acarretando em menor permanência de seus resíduos sobre o solo. Em regiões e em épocas de cultivo onde temperatura e umidade são altas, como no verão do Cerrado, Seguy et al. (1997) indicam a necessidade de 11 a $12 \mathrm{t} \mathrm{ha}^{-1}$ de matéria seca produzidas anualmente para o cultivo de grãos, devido à rapidez de decomposição da palhada. A matéria seca atingiu $4,4 \mathrm{tha}^{-1}$ para o milho e 4,3 t ha $^{-1}$ para o sorgo-sudão, 3,8 tha $^{-1}$ para o consórcio de milho com mucuna-preta e $3,1 \mathrm{tha}^{-1}$ para o milheto. Esses resultados podem ser explicados pelo manejo das plantas de cobertura, que foi realizado aos 57 DAS (dias após semeadura). O manejo efetuado em um período curto se deve à necessidade de uso intensivo de uma mesma área pelo produtor de hortaliças, com vários ciclos culturais durante o ano, o que difere do produtor de grãos. Além disso, um dos fatores que pode ter contribuído para a menor permanência de resíduos foi o tipo de implemento utilizado para o manejo (triturador) pois, apesar de distribuir os restos culturais homogeneamente, os deixa em pequenos pedaços. A intensidade de chuvas no período também pode ter contribuído para a decomposição mais rápida destes resíduos $(701,43 \mathrm{~mm}$ de novembro/06 a janeiro/07). Deve-se considerar também que, no caso do cultivo de hortaliças, é necessário estar atento a problemas fitossanitários, principalmente com doenças de solo que podem ser favorecidas pelo excesso de restos culturais junto às plantas. Assim, quantidades muito grandes de resíduos culturais não são desejáveis em plantios de hortaliças. Este é outro fator que leva ao manejo precoce das plantas de cobertura, de modo a se buscar a viabilidade do plantio direto em hortaliças para sua adoção em áreas de produção.

O curto ciclo das plantas de cobertura e, conseqüentemente menor produção de biomassa e permanência de seus resíduos sobre o solo contribuíram para que não fossem observadas diferenças significativas entre as plantas de cobertura.

A diferença significativa entre a produtividade das cultivares avaliadas (Tabela 1) deve-se basicamente ao potencial produtivo diferenciado de cada uma delas, isto é, ao seu potencial genético, considerando as condições ambientais do experimento. Cultivares híbridas também possuem estabilidade fenotípica e capacidade de produção em diferentes condições edafoclimáticas (homeostase genética), o que pode explicar os bons níveis de produtividade apresentados para as cultivares no verão, época que não coincide com a recomendação de cultivo para estas cultivares, com exceção de Green Storm Bonanza e HECB01-06. Há que se considerar, ainda que o local do experimento apresenta clima relativamente ameno, se comparado a outros locais do Planalto Central, em função de sua altitude.

Observaram-se diferenças significativas na produtividade total e comercial das cultivares (Tabela 2). A cultivar Avenger apresentou produtividade total significativamente maior que as demais, com 13,2 tha $^{-1}$, superando os resultados obtidos no verão por Trevisan et al. 
Tabela 1. Produtividade de brócolos, em $\mathrm{t} \mathrm{ha}^{-1}$, de acordo com cultivares e plantas de cobertura (broccoli yield, in $\mathrm{t}$ ha $\mathrm{a}^{-1}$, according to cultivars and cover crops). Brasília, Embrapa Hortaliças, 2007.

\begin{tabular}{|c|c|c|c|c|c|c|}
\hline Cultivar & Convencional & Milho & Milho + Mucuna & Milheto & Sorgo Sudão & Médias \\
\hline Avenger & 12,6 & 14,8 & 13,6 & 12,4 & 12,7 & $13,2 \mathrm{a}$ \\
\hline Legacy & 9,4 & 10,2 & 11,6 & 10,8 & 10,9 & $10,6 \mathrm{~b}$ \\
\hline Grandisimo & 8,9 & 10,6 & 10,5 & 10,0 & 11,9 & $10,4 \mathrm{~b}$ \\
\hline Demoledor & 7,8 & 8,3 & 8,7 & 6,3 & 7,4 & $7,7 \quad \mathrm{c}$ \\
\hline $\begin{array}{l}\text { Green Storm } \\
\text { Bonanza }\end{array}$ & 7,1 & 7,6 & 7,7 & 7,5 & 8,0 & $7,6 \mathrm{c}$ \\
\hline HECB-01-06 & 4,6 & 4,8 & 5,7 & 5,5 & 3,9 & $4,9 \quad \mathrm{~d}$ \\
\hline Média & 8,4 & 9,4 & 7,9 & 8,8 & 9,2 & $9,1 \mathrm{~ns}$ \\
\hline
\end{tabular}

${ }^{1}$ Cultivares com médias seguidas pela mesma letra na coluna não diferem entre si pelo teste de Scott-Knott, em nível de $5 \%$ de probabilidade de erro; ns= não significativo (means followed by the same letter, in the column, did not differ from each other, Scott-Knott's test, $\mathrm{p}<0.05$ ).

Tabela 2. Produtividade de inflorescências total e comercial e peso médio da inflorescência de brócolos em função da cultivar (total and commercial yield and average weight of broccoli curds, according to cultivars). Brasília, Embrapa Hortaliças, 2007.

\begin{tabular}{|c|c|c|c|}
\hline \multirow{2}{*}{ Cultivar } & \multicolumn{2}{|c|}{ Produtividade } & \multirow{2}{*}{$\begin{array}{c}\text { Peso médio } \\
\text { (g) }\end{array}$} \\
\hline & total (t ha- $\left.{ }^{1}\right)$ & comercial (t ha- $\left.{ }^{1}\right)$ & \\
\hline Avenger & $13,2 \mathrm{a}$ & $13,2 \mathrm{a}$ & $457,5 \mathrm{a}$ \\
\hline Legacy & $10,6 \mathrm{~b}$ & $10,5 \mathrm{~b}$ & $370,8 \quad b$ \\
\hline Grandisimo & $10,4 \quad b$ & $10,3 \quad b$ & $363,0 \quad b$ \\
\hline Demoledor & $7,7 \quad \mathrm{c}$ & $7,3 \quad \mathrm{c}$ & $270,0 \quad c$ \\
\hline Green Storm Bonanza & 7,6 & 7,5 & 265,0 \\
\hline HECB-01-06 & 4,9 & 4,6 & 172,7 \\
\hline CV $(\%)$ & 14,06 & 14,60 & 14,41 \\
\hline
\end{tabular}

Cultivares com médias seguidas pela mesma letra nas colunas, dentro de cada variável, não diferem entre si pelo teste de Scott-Knott, em nível de 5\% de probabilidade de erro (means followed by the same letter, in the column, did not differ from each other, Scott-Knott's test, $\mathrm{p}<0.05)$.

(2003) no Rio Grande do Sul com as cultivares Green River, Baron e Hanamidori com $12,8 \mathrm{tha}^{-1}, 10,8 \mathrm{tha}^{-1}$ e 101 $\mathrm{t} \mathrm{ha}^{-1}$, respectivamente; e no inverno por Lyra Filho et al. (1997) em Pernambuco com as cultivares Hanamidori e Legacy, respectivamente com $8,8 \mathrm{t} \mathrm{ha}^{-1} \mathrm{e} 6,4 \mathrm{t}$ ha ${ }^{-1}$, e Melo \& Giordano (1995) no Distrito Federal com as cultivares Legacy e Sabre, respectivamente com 9,4 e 13,0 t $\mathrm{ha}^{-1}$. As cultivares Legacy e Grandisimo não diferiram entre si, com produtividade de 10,6 e 10,4 $\mathrm{tha}^{-1}$, respectivamente, resultados semelhantes aos obtidos pelos autores citados (Trevisan et al., 2003; Lyra Filho et al., 1997; Melo \& Giordano, 1995). A cultivar Green Storm Bonanza e o material HECB-0106 obtiveram, respectivamente, 7,6 t $\mathrm{ha}^{-1}$ e $4,9 \mathrm{t} \mathrm{ha}^{-1}$. As produtividades obtidas são extremamente satisfatórias e o cultivo do brócolos nesta época permite portanto a ampliação do período de colheita pois, de acordo com Silva (1997), embora o plantio de verão seja menos produtivo, a rentabilidade do cultivo é favorecida por preços mais altos em virtude da colheita ocorrer no período de entressafra.

As cultivares apresentaram diferenças significativas quanto à produtividade comercial (plantas com peso acima de 100 g e nota mínima 2 para aspecto visual). A cultivar Avenger, apresentou todas as plantas como sendo comercias, com produtividade de 13,2 $\mathrm{t} \mathrm{ha}^{-1}$, seguida das cultivares Legacy e Grandisimo, com 10,5 $\mathrm{t} \mathrm{ha}^{-1}$ e 10,3 $\mathrm{t} \mathrm{ha}^{-1}$, respectivamente (Tabela 2). Para o peso médio de inflorescências, a cultivar Avenger apresentou $458 \mathrm{~g}$, seguida das cultivares Legacy e Grandisimo, com médias de
371 e 363 g, respectivamente. As cultivares Green Storm Bonanza, Demoledor e o material HECB-01-06 não diferiram entre si, com médias respectivamente de 270, 265 e $173 \mathrm{~g}$ (Tabela 2). Estas cultivares possuem potencial, tanto para venda in-natura quanto em embalagens individuais para balcões frigoríficos de supermercados, como normalmente ocorre no DF e região.

O índice de aspecto visual de inflorescências, característica importante na cultura estudada, foi significativamente superior na cultivar Avenger, com nota 4,0 (levemente deteriorada, 1 a 9\%), seguido pela cultivar Green Storm Bonanza com nota 3,7. Legacy com nota 3,0 (moderadamente deterioradas, 10 a 39\%). As cultivares Grandisimo, Demoledor e o material HECB-01-06 obtiveram notas médias de 2,9, 2,8 e 2,7 , respectivamente. $\mathrm{O}$ aspecto visual das inflorescências é essencial para a comercialização in natura e para o processamento. Assim, cultivares com notas maiores constituem-se em boa opção para ampliar a disponibilidade de materiais para processamento e congelamento durante o ano (Tabela 3).

Com relação à granulometria, as correlações ficaram, em média, próximas a 0,80 , o que permitiu tomar o peso (mg) como medida para se avaliar a granulometria, característica de avaliação muito mais fácil que o tamanho dos botões florais. Houve diferença entre cultivares, com o material HECB-01-06 apresentando maior granulometria, com 114,3 mg. O material HECB-01-06

${ }^{1}$ MELO PE (Embrapa Hortaliças), informação pessoal, 2006. 
Tabela 3. Índice de aspecto visual das inflorescências (escala de notas variando de 1 a $5 ; 1=$ não comerciais, extremamente defeituosas; $2=$ comerciais defeituosas; $3=$ moderadamente defeituosas; $4=$ levemente defeituosas; $5=$ sem defeitos aparentes), diâmetro médio da inflorescência, primeira colheita e ciclo médio em função da cultivar (visual aspect of broccoli curds (scale from 1 to $5 ; 1=$ non commercial with extreme defects; $2=$ commercial with defects; $3=$ moderate defects; $4=$ light defects; $5=$ no apparent defects), average diameter, first harvest and medium cycle according to cultivars). Brasília, Embrapa Hortaliças, 2007.

\begin{tabular}{lccccc}
\hline Cultivar & $\begin{array}{c}\text { Índice de aspecto } \\
\text { visual }\end{array}$ & $\begin{array}{c}\text { Diâmetro } \\
(\mathbf{c m})\end{array}$ & $\begin{array}{c}\text { Granulometria } \\
(\mathbf{m g})\end{array}$ & $\begin{array}{c}\mathbf{1}^{\mathrm{a}} \text { colheita } \\
\text { (dias) }\end{array}$ & $\begin{array}{c}\text { Ciclo médio } \\
\text { (dias) }\end{array}$ \\
\hline Avenger & $4,0 \mathrm{a}$ & $15,3 \mathrm{a}$ & $42,5 \mathrm{a}$ & $77 \mathrm{a}$ & $86 \mathrm{a}$ \\
Legacy & $3,0 \mathrm{c}$ & $15,1 \mathrm{a}$ & $56,5 \mathrm{a}$ & $78 \mathrm{a}$ & $85 \mathrm{a}$ \\
Grandisimo & $2,8 \mathrm{c}$ & $15,5 \mathrm{a}$ & $31,9 \mathrm{a}$ & $76 \mathrm{a}$ & $84 \mathrm{a}$ \\
Demoledor & $2,8 \mathrm{c}$ & $13,5 \mathrm{~b}$ & $34,4 \mathrm{a}$ & $75 \mathrm{a}$ & $84 \mathrm{a}$ \\
Green Storm Bonanza & $3,7 \mathrm{~b}$ & $13,3 \mathrm{~b}$ & $39,7 \mathrm{a}$ & $72 \mathrm{~b}$ & $78 \mathrm{~b}$ \\
HECB-01-06 & $2,7 \mathrm{c}$ & $13,1 \mathrm{~b}$ & $114,3 \mathrm{~b}$ & $57 \mathrm{c}$ & $63 \mathrm{c}$ \\
\hline CV (\%) & 11,86 & 9,94 & 73,04 & 4,45 & 4,10 \\
\hline
\end{tabular}

Cultivares com médias não seguidas por mesma letra, dentro de cada variável, diferem entre si pelo teste de Scott-Knott, em nível de 5\% de probabilidade de erro (means followed by the same letter, in the column, did not differ from each other, Scott-Knott's test, $\mathrm{p}<0.05$ ).

Tabela 4. Variação de temperatura na superfície e às profundidades de $5,10,15$ e $20 \mathrm{~cm}$ no cultivo de brócolos no verão utilizando diferentes plantas de cobertura (soil temperature variations on surface and at $5,10,15$ and $20 \mathrm{~cm}$ depth in broccoli production using different cover crops). Brasília, Embrapa Hortaliças, 2007.

\begin{tabular}{lcllll}
\hline Cultivar & Superfície & $\mathbf{5} \mathbf{~ c m}$ & $\mathbf{1 0} \mathbf{~ c m}$ & $\mathbf{1 5} \mathbf{~ c m}$ & $\mathbf{2 0} \mathbf{~ c m}$ \\
\hline Milheto & $29,6 \mathrm{a}$ & $27,6 \mathrm{a}$ & $26,3 \mathrm{a}$ & $25,3 \mathrm{a}$ & $25,0 \mathrm{a}$ \\
Milho & $29,3 \mathrm{a}$ & $28,0 \mathrm{a}$ & $26,3 \mathrm{a}$ & $26,0 \mathrm{a}$ & $24,6 \mathrm{a}$ \\
Milho + Mucuna & $29,6 \mathrm{a}$ & $27,6 \mathrm{a}$ & $26,3 \mathrm{a}$ & $25,6 \mathrm{a}$ & $25,3 \mathrm{a}$ \\
Sorgo Sudão & $29,3 \mathrm{a}$ & $27,6 \mathrm{a}$ & $26,3 \mathrm{a}$ & $25,6 \mathrm{a}$ & $25,0 \mathrm{a}$ \\
Convencional & $31,6 \mathrm{~b}$ & $29,6 \mathrm{~b}$ & $27,6 \mathrm{~b}$ & $26,6 \mathrm{a}$ & $25,3 \mathrm{a}$ \\
\hline CV $(\%)$ & 1,98 & 1,84 & 1,85 & 1,80 & 1,46 \\
\hline
\end{tabular}

${ }^{1}$ Médias seguidas pela mesma letra nas colunas, para cada profundidade, não diferem entre si pelo teste Scott-Knott, a 5\% de probabilidade (means followed by the same letter, in the column, did not differ from each other, Scott-Knott's test, $\mathrm{p}<0.05$ ).

apresentou maior granulometria por ser proveniente do cruzamento entre linhagens de brócolos obtidas na Embrapa Hortaliças que possuem, em sua genealogia, cruzamentos com plantas de brócolos do tipo ramoso. O brócolos do tipo ramoso caracteriza-se por apresentar botões florais maiores e mais frouxos que as plantas de inflorescência única. Este material foi desenvolvido com o objetivo de introduzir adaptação às condições de cultivo na região de Brasília dos genótipos de inflorescência única.

O elevado coeficiente de variação observado $(73,4 \%)$ na granulometria pode ser explicado, em parte, pela grande variabilidade de tamanho de botões florais dentro de uma mesma inflorescência. Geralmente, os botões florais localizados nas extremidades da inflorescência são mais leves e frouxos por terem se desenvolvido primeiro.
Como os botões foram escolhidos aleatoriamente, de forma a representar toda a granulometria existente na inflorescência e não apenas aquela mais fina, esta variação está expressa no elevado coeficiente de variação (Tabela 3 ).

O material HECB-01-06 foi mais precoce, tendo o início de colheita aos 57 DAT (dias após transplante), seguido da cultivar Green Storm Bonanza, iniciando a colheita aos 72 DAT, mais precoces que as demais. Este aspecto é interessante para escolha de materiais com menor permanência em campo, visando a sucessão de culturas (Tabela 3). O ciclo médio foi de 63 dias para o material HECB-01-06, seguido da cultivar Green Storm Bonanza com 78 dias, mais precoces que as demais (Tabela 3).

As temperaturas do solo, medidas durante as fases de expansão e desenvolvimento das folhas propostas por Kimoto (1993), apresentaram médias significativas para as medições feitas na superfície do solo, a 5 e a $10 \mathrm{~cm}$ de profundidade, não apresentando diferenças significativas nas profundidades de 15 e $20 \mathrm{~cm}$, observando-se estabilidade durante o período de avaliação, independente das diferentes condições de radiação solar. As temperaturas do solo nas parcelas com as plantas de cobertura foram de 2 a $2,3^{\circ} \mathrm{C}$ inferiores na superfície do solo, de 1,6 a $2^{\circ} \mathrm{C}$ inferiores a $5 \mathrm{~cm}$ de profundidade, e $1,3^{\circ} \mathrm{C}$ inferior a $10 \mathrm{~cm}$ de profundidade, quando comparadas ao PC, sem cobertura do solo (Tabela 4). Estes resultados indicam que no período em que o solo se mantém coberto ocorre uma redução de suas temperaturas próximas ao coleto das plantas e nas profundidades acima mencionadas, favorecendo o desenvolvimento das plantas.

As cultivares avaliadas apresentaram diferenças significativas quanto à distribuição semanal do percentual de plantas colhidas. O material HECB-01-06 apresentou $52 \%$ do total das plantas sendo colhidas entre 57 e 63 DAT, o que corresponde a 2,6 $\mathrm{t} \mathrm{ha}^{-1}$. Ainda destaca-se, que $90 \%$ da produção total foi colhida até os 70 DAT, correspondendo a 4,3 t $\mathrm{ha}^{-1}$ de um total de $4,9 \mathrm{t} \mathrm{ha}^{-1}$.

A cultivar Green Storm Bonanza teve seu pico de produção entre $71 \mathrm{e}$ 77 DAT, com $60 \%$ do total colhido neste período. Em termos de produção, 
a cultivar Green Storm Bonanza teve aproximadamente 4,5 $\mathrm{t} \mathrm{ha}^{-1}$ colhidas neste período, de um total de 7,6 $\mathrm{tha}^{-1}$. A cultivar Demoledor teve colheita praticamente constante dos 71 aos 93 DAT, com aproximadamente $78 \%$ da produção sendo colhida neste período, correspondendo a $6,0 \mathrm{t} \mathrm{ha}^{-1}$ de um total de $7,7 \mathrm{tha}^{-1}$.

A cultivar Grandisimo iniciou a colheita aos 71 DAT, com 74\% da produção sendo colhida até os 93 DAT, ou 7,5 $\mathrm{t} \mathrm{ha}^{-1}$ de um total de $10,3 \mathrm{t} \mathrm{ha}^{-1}$. As cultivares Avenger e Legacy apresentaram-se mais tardias, com 40 a $50 \%$ do total sendo colhido entre 85 e 91 DAT, ou 4,2 e 5,3 t ha-1, respectivamente, de um total de 13,2 $\mathrm{t} \mathrm{ha}^{-1}$ e 10,6 $\mathrm{t} \mathrm{ha}^{-1}$. As diferenças apresentadas permitem um planejamento da produção com base no conhecimento do ciclo de cada cultivar, sendo esta uma informação importante para o produtor visando o atendimento de mercado.

O desempenho das cultivares avaliadas revela a possibilidade de produzir brócolos de inflorescência única no verão, destacando-se as cultivares Avenger, seguida de Legacy e Grandisimo. Existe a possibilidade destas serem indicadas para plantios comerciais em regiões com condições edafoclimáticas semelhantes ao DF, tanto para comércio in-natura quanto para processamento e congelamento no DF. O plantio de brócolos em PD, independente das plantas de cobertura avaliadas, foi capaz de proporcionar produtividades semelhantes às obtidas no PC. Portanto, tendo em vista a manutenção de elevados níveis de produtividade no PD, é recomendável sua adoção, considerando-se os reconhecidos benefícios proporcionados pelo Sistema Plantio Direto, como a melhoria das características físicas, químicas e biológicas de solo, a maximização dos recursos água e energia e a minimização dos processos erosivos.

\section{REFERÊNCIAS}

BURLE ML; CARVALHO AM; AMABILE RF; PEREIRA J. 2006. Caracterização das espécies de adubo verde. In: CARVALHO AM; AMABILE RF. (editores). Cerrado: adubação verde, Planaltina-DF: Embrapa Cerrados, p.71-142.

BRAZ LT; VARGAS PF; CHARLO HCO; CASTOLDI R. 2007. Acúmulo de macronutrientes durante o ciclo de couve brócolos 'Legacy'. In: CONGRESSO BRASILEIRO DE OLERICULTURA. Resumos do XLVII CBO Porto Seguro: SOB (CD-ROM).

CEAGESP. 2000. Classificação de couveflor. Centro de qualidade em Horticultura (Folder).

DIXON GR; DICKSON MH. 2006. Vegetable brassicas and related Crucifers. Wallingford: CABI. 416 p. (Crop Production Science in Horticulture, Series 14).

EMBRAPA. 1999. Manual de análises químicas de solos, plantas e fertilizantes. Brasília: Embrapa Solos/Embrapa Informática Agropecuária/ Embrapa Comunicação para Transferência de Tecnologia, $370 \mathrm{p}$.

FERREIRA DF. 1999. Sistema para análise de variância para dados balanceados (SISVAR). Lavras: UFLA. 92 p.

FREITAS PL. 2002. Sustentabilidade: Harmonia com a Natureza. Agroanalysis 22: 12-17.

GASPARIM E; RICIERI RP; SILVA SL; DALLACORT R; GNOATTO E. 2005. Temperatura no perfil do solo utilizando duas densidades de cobertura e solo nu. Acta Scientiarum 27: 107-115.

KIMOTO T. 1993. Nutrição e Adubação de repolho, couve-flor e brócolis. In: Nutrição e adubação de hortaliças. Jaboticabal, 1993. Anais... Jaboticabal, UNESP. p.149-178.

LANDERS JN. 1995. Fascículo de experiências de plantio direto no cerrado. Brasília: APDC. $261 \mathrm{p}$.

LYRA FILHO HP; MARANHÃO EHA; MARANHÃO EAA; RODRIGUES VJLB. 1997. Competição de cultivares e híbridos de brócolos (Brassica oleracea var. italica L.) na Zona da Mata do Estado de Pernambuco. In: CONGRESSO BRASILEIRO DE OLERICULTURA, 37. Resumos do XXXVII CBO Manaus: SOB (suplemento).

MELO PE; GIORDANO LB. 1995. Características agronômicas e para processamento de híbridos comerciais e experimentais de brócolos de inflorescência única. Horticultura Brasileira
13: 95 .

MELO PE; GIORDANO LB; SILVA C. 1994. Avaliação de híbridos experimentais de brócolos de inflorescência única. Horticultura Brasileira 12: 90.

SANTA CATARINA. 2001. Secretaria de Estado do Desenvolvimento Rural e da Agricultura. Empresa de Pesquisa Agropecuária e Extensão Rural - EPAGRI. Cultivares catarinenses: um modelo de pesquisa. Agropecuária Catarinense 14:2.

SEABRA JÚNIOR S. 2005. Influência de doses de nitrogênio e potássio na severidade à podridão negra e na produtividade de brócolis tipo inflorescência única. Botucatu: UNESP. 90 p. (Tese doutorado).

SEGUY L; BOUZINAC S; TRENTINI A; CORTES NA. 1997. Gestão da fertilidade de culturas mecanizadas nos trópicos úmidos: o caso das frentes pioneiras nos cerrados e florestas úmidas no centro norte do Mato Grosso. In: PEIXOTO RTG; AHRENS DC; SAMAHA MJ. (Ed.). Plantio Direto: o caminho para uma agricultura sustentável. Ponta Grossa: Iapar, p.125-157.

SIDIRAS N; PAVAN MA. 1986. Influência do sistema de manejo na temperatura do solo. Revista Brasileira de Ciência do Solo 10: 181-184.

SILVA G. 1997. Brócolis: o primo rico. Globo Rural 143: 25-27.

SPEHAR CR; LANDERS JN. 1997. Características, limitações e futuro do plantio direto nos cerrados. In: SEMINÁRIO INTERNACIONALDO SISTEMAPLANTIO DIRETO, 2. Anais... Passo Fundo-RS: Embrapa CNPT. p.127-131.

SPEHAR CR; LARA CABEZAS WAR. 2001. Introdução e seleção de espécies para a diversificação do sistema produtivo nos cerrados. In: LARA CABEZAS WAR; FREITAS PL. (Eds.) Plantio Direto na Integração Lavoura-Pecuária. UberlândiaMG: UFU. p.179-188.

TAVARES CAM. 2000. Brócolos: O cultivo da saúde. Revista Cultivar HF 2: 20-22.

TRANI PE; PASSOS FA; AZEVEDO JA; TAVARES M. 1996. Brócolos, couve-flor e repolho. In: RAIJ B; CANTARELLA H; QUAGGIO JA; FURLANI AMC. (eds.) Recomendação de adubação e calagem para o Estado de São Paulo. Campinas: Instituto Agronômico/ Fundação IAC. p. 175. (Boletim Técnico, 100).

TREVISAN JN; MARTINS GAK; DAL'COL LUCIO A. 2003. Rendimento de cultivares de brócolis semeadas em outubro na região centro do Rio Grande do Sul. Ciência Rural 33: 233-239. 